\title{
MODELLING OF SOIL DAMPING FOR SEISMIC GROUND RESPONSE BY NONLINEAR FINITE ELEMENT ANALYSIS
}

\author{
A. F. Zidan
}

\begin{abstract}
In this paper, the nonlinear dynamic behavior of clayey soil using $2 \mathrm{D}$ finite element analyses is presented. This paper presents comparative analyses of seismic response by different numerical approaches. The behavior of two types of soil represented the soft and stiff clay is investigated under effect of three different acceleration time histories. The amplification functions of seismic signals obtained by 1D equivalent linear viscoelastic analyses performed in the frequency domain is used to evaluate the initial values of Rayleigh damping ( $\alpha \mathrm{R}$ and $\beta \mathrm{R}$ ) coefficients to perform the nonlinear finite element analyses. The influences of type of soil and peak ground acceleration on the nonlinear dynamic behavior of soil are studied. The results show a contraction of peak ground acceleration profile and the spectra as compared to the equivalent linear analysis especially in the uppermost portion of the deposit. The rate of increase of shear strain during ground shaking and the permanent shear strain increases as increase of peak ground acceleration for soft soil and linearly for stiff clay. The results obtained by the results indicate that the equivalent linear analysis should not be considered as a right way to modeling strong motion earthquakes especially for soft clay deposit.
\end{abstract}

Keywords: Seismic ground response analysis, Rayleigh damping, finite element analysis, nonlinear analysis

\section{Introduction}

There are two main numerical methods to solve the wave propagation problem namely linear or equivalent linear analysis method (frequency domain solution) and nonlinear analysis method (time domain solution). However the equivalent linear analysis is widely used in engineering practice due its simplicity [1-2]. It is essentially a linear method does not account for the change in soil properties during the ground motion. In the current study the nonlinear analysis is used to investigate the behavior of soil throughout the

Faculty of engineering- Beni-Suef University Egypt earthquake duration uses a step by step integration scheme and more accurately simulates the true nonlinear behavior of soils.

Nowadays, the finite element analysis is available to solve the wave propagation problems. The behavior of soil can be analyzed using linear, equivalent linear or nonlinear constitutive models. Permanent strain in soil subjected to earthquake forces was also obtained using non linear finite element analysis. The stresses, deformations and the force acting on the structural elements that interacts with the soil can be predicted in one single analysis [3-6]. Various approaches used based on finite element method mainly vary with the constitutive model adopted to model the behavior of soil [7-10]. Park and Hashash [11] used nonlinear time-domain site response analysis to capture the soil hysteretic response and nonlinearity due to medium and large ground motions. Soil damping is captured through the hysteretic energy dissipating response, and one can use their proposed formulations in nonlinear site response analysis. Ciro Visone et al. [12] presented a comparative study on frequency and time domain analyses for the evaluation of the seismic response of subsoil to the earthquake shaking by different computer programs. Amorosi et al. [13] performed 2D finite element analysis of seismic ground response of a clayey deposit, using linear viscoelastic and visco-elsto-plastic constitutive models, the viscous and linear elastic parameters are selected according to a novel calibration strategy, leading to FE results comparable to those obtained by $1 \mathrm{D}$ equivalent-linear visco-elastic frequencydomain analyses.

It is well known that the linear and equivalent linear analysis provides the reasonable results for seismic ground problems but these methods remain approximate methods to simulate the actual nonlinear processes [14]

The current study presents an appropriate method to model the soil damping parameters in 2D nonlinear analysis performed in time domain. Also, this paper presents A comparative study on a set of 1D ground response analyses performed in the frequency domain using commercial computer program DEEPSOIL [15] with the corresponding nonlinear analyses based on 2D finite element obtained by PLAXIS program [16]. The nonlinear analysis is used to investigate the relationship 
Proc. of the Third Intl. Conf. on Advances in Civil and Structural Engineering - CSE 2015

Copyright (C) Institute of Research Engineers and Doctors, USA .All rights reserved.

ISBN: 978-1-63248-057-6 doi: 10.15224/ 978-1-63248-057-6-49

between maximum shear strain during earthquake motion and permanent shear strain with the peak ground acceleration.

The analyses are performed on two soil profiles under the effect of three input seismic motions. the amplification functions of the signals obtained by 1D equivalent linear visco-elastic analyses is used to evaluate the initial profiles of Rayleigh damping coefficients in the nonlinear finite element analysis as shown later. Also the nonlinear analysis is used to investigate the relationship between maximum shear strain during earthquake motion and permanent shear strain with the peak ground acceleration.

\section{Soil profile}

Two ideal $60 \mathrm{~m}$ thick soil deposits were considered in the current analyses. The first deposit consists of single stratum of soft clay, while the second deposit is composed of stiff clay. The physical and mechanical parameters for both strata are shown in table 1 . The shear wave velocity of soils varies in proportion to $(\mathrm{pm}) 1 / 4$ where $\mathrm{pm}$ is effective mean confinement pressure. The profile of small strain shear stiffness $G_{0}$ with depth was calculated by following equation:

$$
\mathrm{G}_{0}=\rho \mathrm{Vs}^{2}
$$

where the parameter $\rho$ is the mass density of soil. The variation of $\mathrm{G}_{0}$ with depth and corresponding shear wave velocity $\mathrm{V}_{\mathrm{s}}$ are reported in Fig. 1. In both deposits, the water table was assumed at the ground level and the small strain damping was considered constant with depth. The variation of $\mathrm{G} / \mathrm{G}_{0}$ and $\mathrm{D} / \mathrm{D}_{0}$ with shear strain level $\gamma$ was defined according the results reported in the literature [17] as function of Ip as shown in Fig. 2.

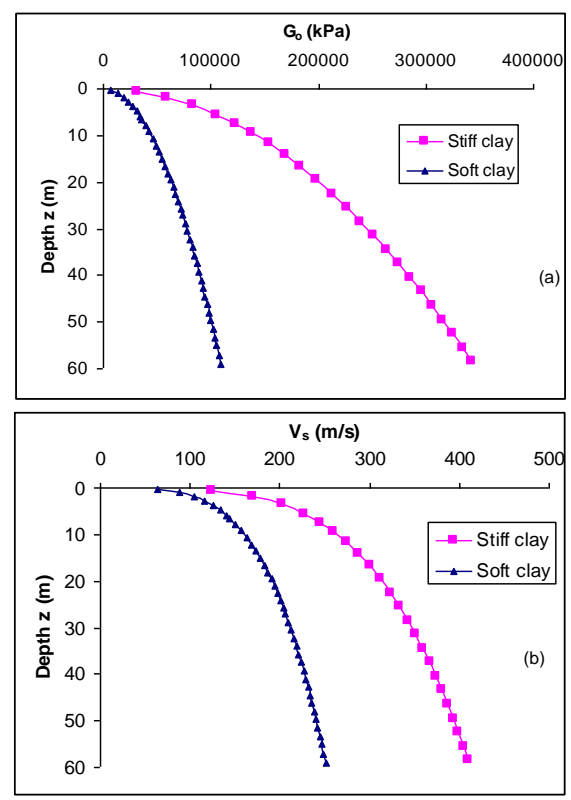

Fig. 1. Soil profile. (a) Profile of the small strain shear modulus ; b) Profile of the shear wave velocity
Table 1.

Physical and mechanical parameters of assumed soil deposit.

\begin{tabular}{|l|l|l|}
\hline \multirow{2}{*}{ Parameters } & \multicolumn{2}{|l|}{ Soil profile } \\
\cline { 2 - 3 } & Stiff clay & Soft clay \\
\hline Plasticity index $I_{p}(\%)$ & 42 & 45 \\
\hline $\begin{array}{l}\text { Unit weight of volume } \gamma \\
\left(\mathrm{kN} / \mathrm{m}^{3}\right)\end{array}$ & 20 & 17 \\
\hline $\begin{array}{l}\text { Coefficient at rest earth } \\
\text { pressure } k_{0}\end{array}$ & 0.61 & 0.66 \\
\hline Friction angle $\phi^{\prime}\left(^{\circ}\right)$ & 23 & 20 \\
\hline Poisson's ratio $v^{\prime}$ & 0.25 & 0.25 \\
\hline Cohesion c' $(\mathrm{kPa})$ & 40 & 10 \\
\hline $\begin{array}{l}\text { Small-strain damping ratio } \\
D_{o}(\%)\end{array}$ & 1 & 1 \\
\hline $\begin{array}{l}\text { Reference Secant modulus } \\
E_{50}^{\text {ref }}(\mathrm{kPa})\end{array}$ & 60000 & 35000 \\
\hline $\begin{array}{l}\text { Reference oedometer } \\
\text { modulus } E_{\text {oed }}^{\text {ref }}(\mathrm{kPa})\end{array}$ & 60000 & 35000 \\
\hline $\begin{array}{l}\text { Reference unloading } \\
\text { reloading modulus } E_{u r}^{r e f} \\
(\mathrm{kPa})\end{array}$ & 180000 & 109000 \\
\hline $\begin{array}{l}\text { Reference confining } \\
\text { pressure } p^{\text {ref }}(\mathrm{kPa})\end{array}$ & 100 & 100 \\
\hline
\end{tabular}
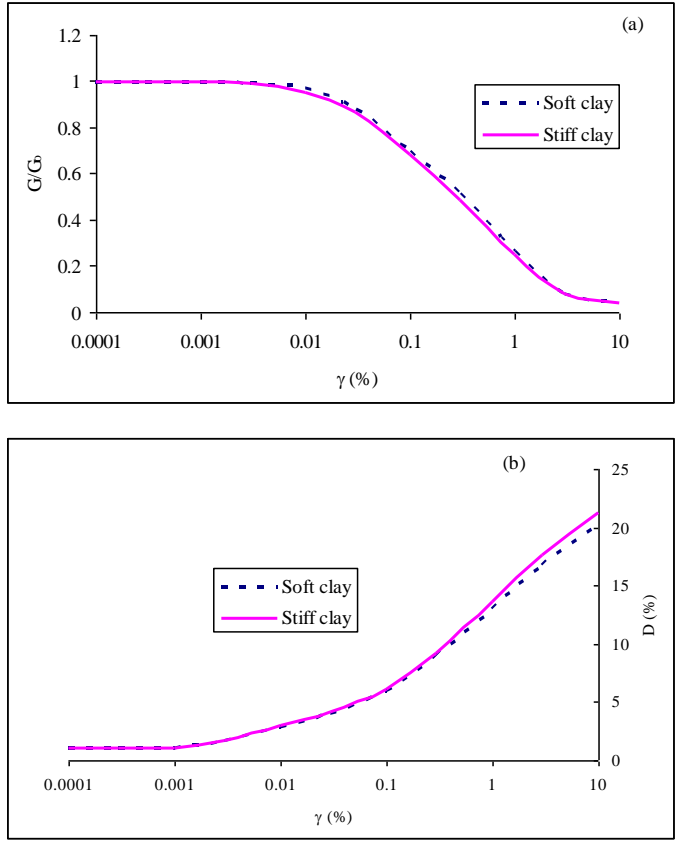

Fig. 2. a) Modulus reduction curve $G / G_{0}$; b) variation of damping ratio $D$ with shear strain $\gamma$

\section{Seismic input motions}

In numerical computation, the earthquake loading is often imposed as an acceleration time-history at the base of the model. To investigate the influence 
of input motion on the nonlinear seismic response of soil layer, three different acceleration time histories were considered, Fig. 3. These motions are obtained using the data base available in DEEPSOIL Hashash et al. 2008 [15] which were effectively used earlier by Choudhury and Savoikar 2009 [2] for equivalent-linear ground response analysis of municipal solid waste material. The earthquake characteristics of these motions like peak ground acceleration, Predominant period and significant duration are also presented in Table 2 . These are derived using Seismo Signal program (see www.SeismoSoft.com).

In equivalent linear analysis, the elastic bed rock was assumed. The main characteristics of elastic bed rock are illustrated in table 3 .

The input seismic signals were considered as applied at the rock outcropping of the deposit. Indeed these earthquake signals are measured at the ground surface but for simplicity we dealt with these motions as artificial earthquake at the bed rock. The corresponding bed rock motions were then calculated by performing an equivalent-linear analysis. The corresponding bed rock motions for two soil profile performed in $2 \mathrm{D}$ analysis are shown in Fig. 4 and Fig. 5.

Table 2.

Main characteristics of the input motions

\begin{tabular}{|l|l|l|l|}
\hline Earthquake & $\begin{array}{l}\text { PGA } \\
(\mathrm{g})\end{array}$ & $\begin{array}{l}\text { Predominant } \\
\text { period }(\mathrm{s})\end{array}$ & $\begin{array}{l}\text { Significant } \\
\text { duration }(\mathrm{s})\end{array}$ \\
\hline Motion 1 & 0.442 & 0.38 & 3.70 \\
\hline Motion 2 & 0.278 & 0.3 & 11.57 \\
\hline Motion 3 & 0.119 & 0.118 & 6.19 \\
\hline
\end{tabular}

Table 3.

Elastic bed rock parameters used in the analyses

\begin{tabular}{|l|l|}
\hline Parameter & Value \\
\hline Mass density $\left(\mathrm{kg} / \mathrm{m}^{3}\right)$ & 2038 \\
\hline Unit weight $\left(\mathrm{kN} / \mathrm{m}^{3}\right)$ & 20 \\
\hline Shear wave velocity $\mathrm{V}_{\mathrm{s}}(\mathrm{m} / \mathrm{s})$ & 1200 \\
\hline
\end{tabular}

\section{Numerical models}

Two types of analyses were performed in the current study using two numerical codes. The first type is one dimensional analysis adopting frequency domain analysis using the equivalent linear visco-elastic code DEEPSOIL [15].

The DEEPSOIL code is widely used for ground response analysis or soil amplification studies as it provides reasonable estimates of ground motion [2]. It is a program for one dimensional site response analysis that performs frequency domain for linear and equivalent linear analysis and time domain for nonlinear analysis. The DEEPSOIL code was used here to predict the ground response adopting the equivalent linear analysis. The equivalent-linear model assumes that the shear modulus $G$ and damping ratio $D$ are function of the shear strain amplitude $\gamma$. The equivalent linear analysis was based on the pioneering work of Idriss and Seed [18], and Seed and Idriss [19] as employed in the widely used program SHAKE [20]. In DEEPSOIL analyses, the profile of small strain stiffness shown in Fig. 1 were discretised by constant stiffness sub-strata of thickness ranging from $3 \mathrm{~m}$ at the base of stratum to $1 \mathrm{~m}$ at the surface. The equivalent linear model employs an iterative procedure in the selection of the shear modulus and damping ratio.

Two dimensional finite element model is performed in the second type of analysis using the PLAXIS code V.8.2 [16]. This code is a commercial finite element program that allows performing stress strain analysis for various types of geotechnical problems. The earthquake analysis can be performed by imposing an acceleration time history at the base of the two dimensional finite element model and solving the equations of motion in time domain by adopting a Newmark type implicit time integration scheme.

In nonlinear analysis the soil was modelled by 15 node triangular finite element. The hardening soil model (hyperbolic stress-strain relation) was used in order to simulate the nonlinear behavior of soil. Hardening-Soil model is the hyperbolic relationship between the vertical strain, $\varepsilon_{l}$, and the deviatoric stress, $q$. The analyses were performed under undrained conditions. In Plaxis program it is possible to specify undrained behavior in an effective stress analysis using effective model parameters [16] [5], [13]. The choice of boundary conditions influences the amount of energy dissipation due to the wave propagation in the ground. The position of the boundary and the kind of mechanical constraints should reproduce, at best, the energy transmission outwards the computation domain. Viscous adsorbent boundaries based on the method described by Lysmer and Kuhlemeyer [21] are a rather widespread procedure. In this case, normal and tangential stress components adsorbed at the boundary location are:

$\sigma_{\mathrm{n}}=-\mathrm{C}_{1} \rho \mathrm{V}_{\mathrm{p}} \mathrm{u}_{\mathrm{n}}$

$\tau=-\mathrm{C}_{2} \rho \mathrm{V}_{\mathrm{s}} \mathrm{u}_{\mathrm{t}}$

where $\rho$ is the density of the material, $V_{p}$ and $V_{s}$ are the compression and shear wave velocities, $u_{n}$ and $\mathrm{u}_{\mathrm{t}}$ are the normal and tangential components of the velocity, $C_{1}$ and $C_{2}$ are relaxation coefficients. Some suggestions exist in literature for the choice of these parameters. The parameters $C_{1}$ and $C_{2}$ are assumed here 1 and 0.25 respectively. The bottom of the mesh is assumed to be rigid. The model of dynamic analysis can be sketched in Fig. 6. The characteristic dimension of the element $\mathrm{h}$ always satisfies the condition $h \leq h_{\max }=V_{s} /(6 \div 7) f_{\max }$ 

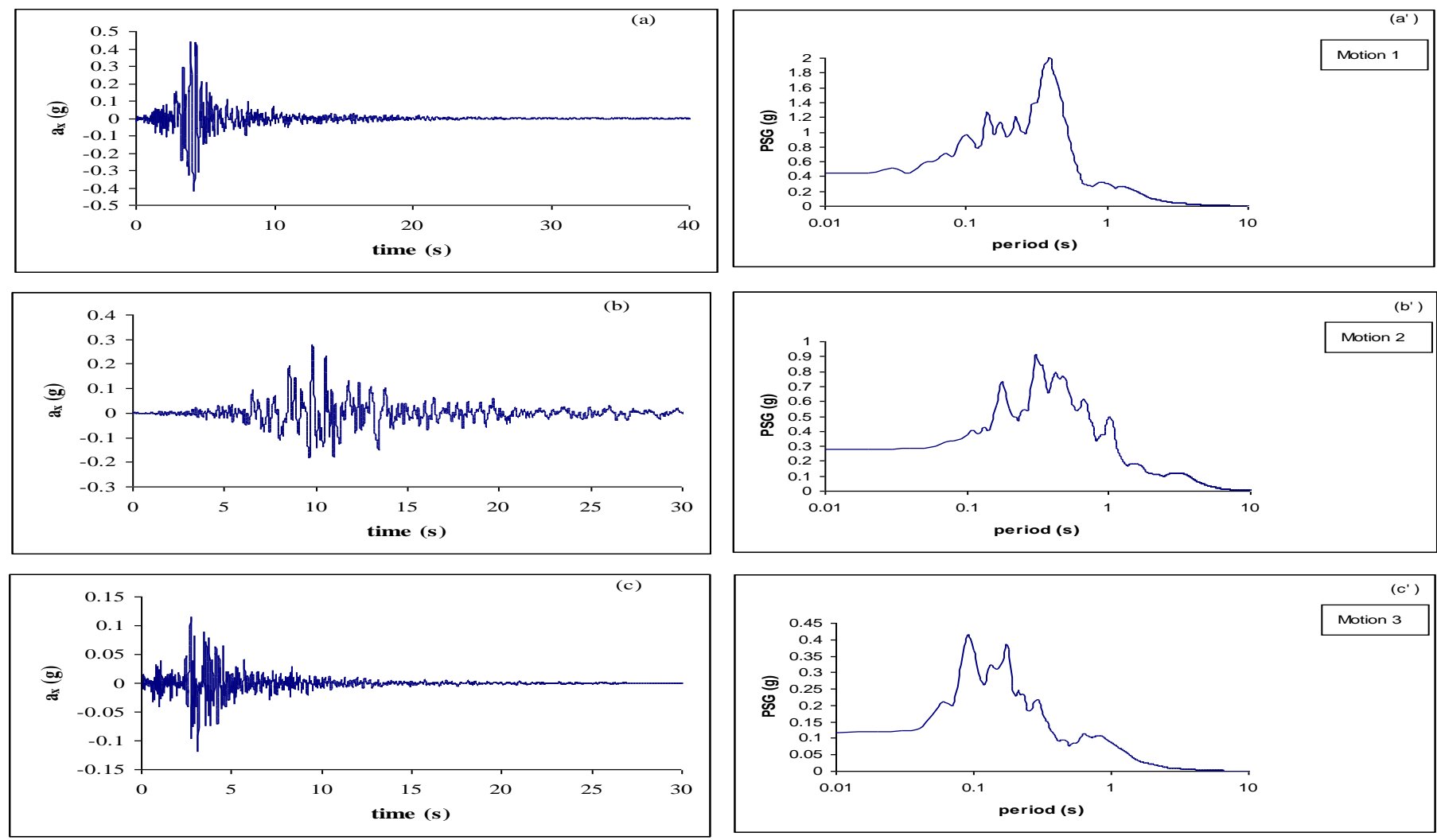

Fig. 3. Seismic input signal of the three selected acceleration time histories and corresponding response spectrum: (a) Motion 1, (b) Motion 2, (c) Motion 3.

where $V_{s}$ is the shear wave velocity and $f_{\max }$ is the maximum frequency of the seismic signal.

The two lateral domains, characterized by a coarse mesh, to reduce the computational costs $[5,13]$. It is characterised by width equal to eight times its height, in order to minimize the effect of boundary conditions on the computed results [23]. The generalized Newmark method [22] is adopted for the time integration under dynamic conditions. The following values of the Newmark parameters were selected in all the analyses illustrated in this paper: $\alpha_{\mathrm{N}}=0.3025$ and $\beta_{\mathrm{N}}=0.6$.

In the PLAXIS code, the Rayleigh damping formulation is implemented and the values of $\alpha_{R}$ and $\beta_{\mathrm{R}}$ are obtained by:

$\left\{\begin{array}{c}\alpha_{R} \\ \beta_{R}\end{array}\right\}=\frac{2 D}{\omega_{m}+\omega_{n}}\left\{\begin{array}{c}\omega_{n} \omega_{m} \\ 1\end{array}\right\}$

where $\omega_{\mathrm{m}}$ and $\omega_{\mathrm{n}}$ are the angular frequencies related to the limits of frequency interval $\left(f_{m}, f_{n}\right)$ over which the viscous damping is equal to or lower than D.

This paper supposes that, the values of $\alpha_{R}$ and $\beta_{R}$ for nonlinear analysis are chosen according to Eq.4 for the frequency interval $\left(f_{m}, f_{n}\right)$ depending on the damping coefficient predicted from the equivalent linear analyses

\section{Calibration of damping ratio for nonlinear analysis}

In fact it is well known that the damping ratio depends on the level of shear strain. In time domain schemes there are two sources of damping: viscous damping, generally introduced through the Rayleigh [24] formulation, and the hysteretic dissipation associated to the irreversible material response. In order to simulate the wave propagation problem through the nonlinear finite element analysis, this paper supposes that the viscous damping ratio that implemented in nonlinear analysis depends on the values of Reyleigh damping coefficient profile predicted from the $1 \mathrm{D}$ analysis performed by DEEPSOIL code. The following steps show the procedure of specify the Reyleigh damping coefficient that used in $2 \mathrm{D}$ nonlinear analyses.

a- Reyleigh damping coefficient $\left(\alpha_{R}\right.$ and $\left.\beta_{R}\right)$ over the thickness soil layer are predicted from 1D analysis. The details of this step are given hereinafter.

b- The previous Reyleigh damping coefficients is used as initial profiles in the nonlinear analysis.

c- New profiles for Reyleigh damping coefficients are predicted from step b depend on the level of shear strain and the frequency interval $\left(\mathrm{f}_{\mathrm{m}}, \mathrm{f}_{\mathrm{n}}\right)$

$\mathrm{d}$ - Step c is repeated ( two to three times) until reach to the constant values $\alpha_{R}, \beta_{R}$ profiles 
Different possible procedure were proposed in the literature to identify the frequency interval $\left(f_{m}, f_{n}\right)$ $[25,26]$. Amorosi et al. [13] presented a new procedure to specify frequency interval in order to obtain a better match between the linear time domain and frequency domain analyses whereas, the first natural frequency $\left(f_{l}\right)$ is selected as $f_{m}$. The value of $f_{n}$ should be selected equal to the frequency where the amplification function gets lower than unity. In the current study this procedure is used to obtain the Reyleigh damping coefficient that used in the first trial of nonlinear analysis.

For example, for the case of soft clay deposit exited by Motion 2 earthquake, Fig.7 shows an example of the amplification function of the seismic signal at $15 \mathrm{~m}$ depth. It shows the frequency interval $f_{m}=0.83 \mathrm{~Hz}$ at the first peak of amplification function and $f_{n}=1.25 \mathrm{~Hz}$. The damping ratio at this depth depending on the maximum shear strain is $8 \%$. From Eq. 4 the corresponding Reyleigh damping coefficient are $\left(\alpha_{R}=0.5014\right.$ and $\left.\beta_{R}=0.0122\right)$. In order to construct the $\alpha_{R}$ and $\beta_{R}$ profiles according to Eq. 4 the values of $f_{m}, f_{n}$, maximum shear strain $\left(\gamma_{\max }\right)$, Damping ratio depend on $\gamma_{\max }$ should be obtained at different depths along the stratum. Fig. 8 shows the initial profiles of
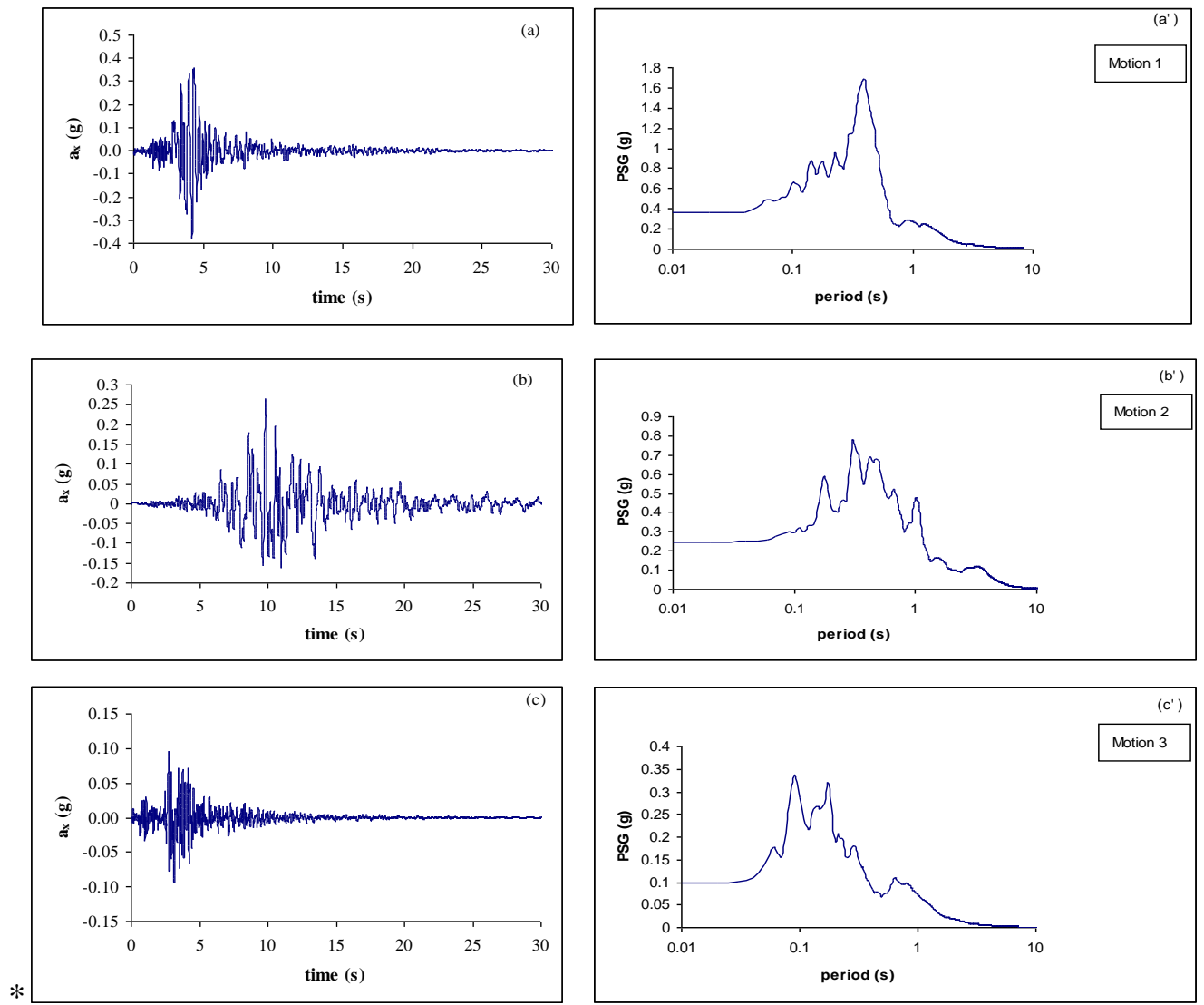

Fig. 4. Acceleration and response spectrum at to the bed rock of the soft clay in 2D analysis: (a)(a') Motion 1, (b)(b') Motion 2, (c)(c') Motion 3. 
Proc. of the Third Intl. Conf. on Advances in Civil and Structural Engineering - CSE 2015

Copyright (C) Institute of Research Engineers and Doctors, USA .All rights reserved.

ISBN: 978-1-63248-057-6 doi: 10.15224/ 978-1-63248-057-6-49
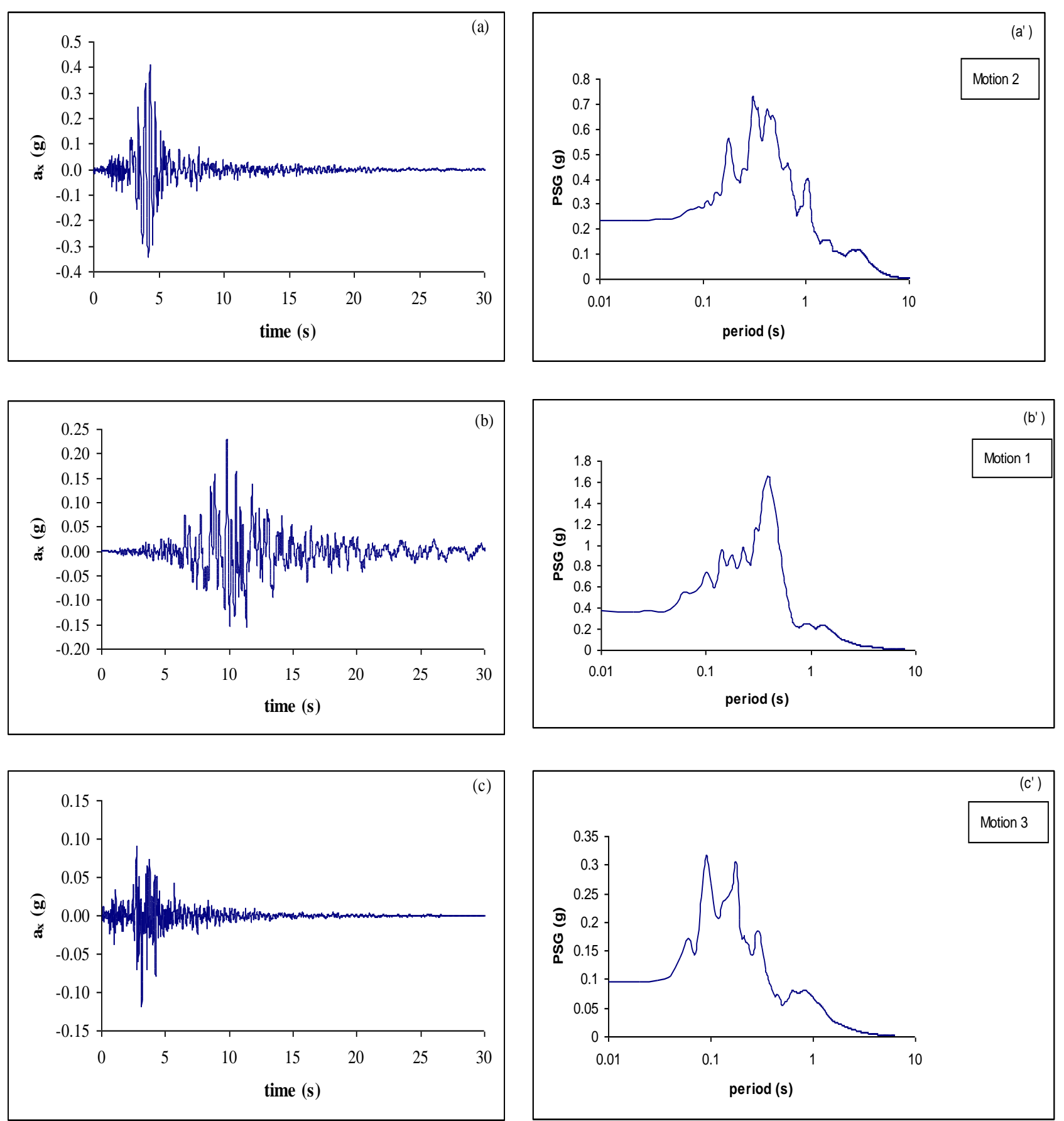

Fig. 5. Acceleration and response spectrum at the bed rock of the stiff clay in 2D analysis: (a) (a') Motion 1, (b) (b') Motion 2, (c) (c') Motion 3.

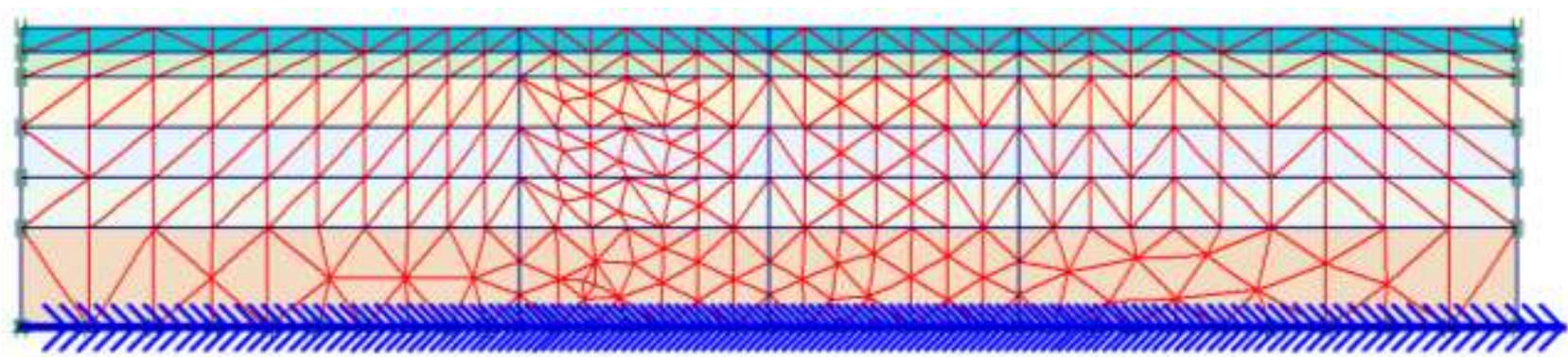

Fig. 6. Sketch of the two dimensional finite element model 


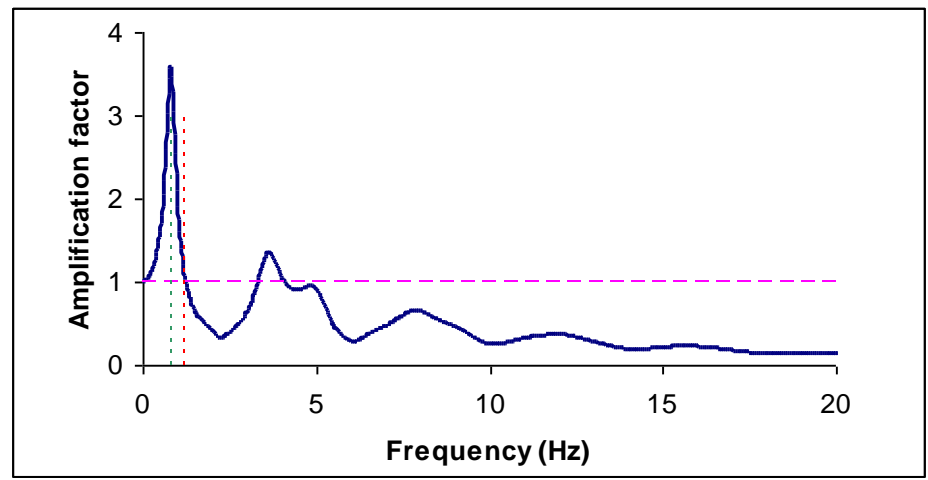

Fig. 7 Amplification function at 15m depth for soft clay deposit and Motion 2 earthquake

\section{Effect of peak ground acceleration on shear strain}

It is well known that the induced shear strain in soil depends on maximum peak ground acceleration in seismic signal. In this section the nonlinear analysis performed with PLAXIS code is used to investigate the effect of peak ground acceleration on the maximum shear strain during ground shaking and the permanent shear strain after the duration of earthquake.

In order to investigate the relationship between the maximum shear strain in soil and maximum peak ground acceleration, Motion 2 earthquake is selected in the current study and scaled to $(0.4,0.8$, $1,1.4,1.8,2)$.

Figure 11 shows an example of the variation of shear strain with time during ground shaking for soft clay deposit at 10 depth and it can be noted that the permanent shear strain in this case is $3 e-2 \%$.

The group of curves presented in Fig. 12 shows the effect of peak acceleration on the maximum shear strain at different depths for stiff clay deposit. It can be observed that the shear strain increases linearly with increase of peak ground acceleration. For soft clay, it can be noted that the rate of maximum shear strain increases as the peak ground acceleration increase as shown in Fig. 13.

Fig. 14 shows the relationship between the permanent shear strain and peak ground acceleration for stiff deposit. It shows that the permanent shear strain increases with increase of peak ground acceleration and the relation can be considered linear. For soft clay, the same trend can be noticed and the rate of increase of the permanent shear strain increases with the increase of peak ground acceleration as shown in Fig. 15. Because the plasticity can be obtained in the nonlinear analysis (plastic analysis) permanent displacement and corresponding variation of the effective stress state occur, significantly modifying the soilstructure interaction in any geotechnical context e.g. [5]. Therefore the results obtained by the equivalent linear analysis should not be considered as a right way to modeling strong motion earthquakes especially for soft clay deposit because the nonlinear analysis does not account for the change in soil properties during the of ground motion.

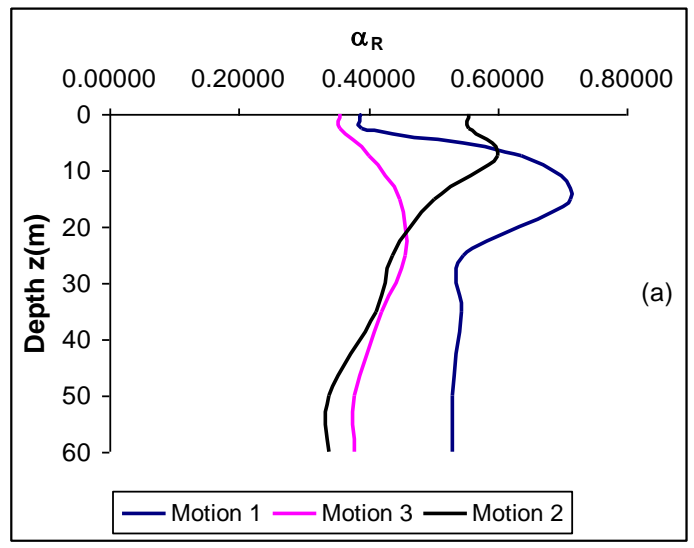


Proc. of the Third Intl. Conf. on Advances in Civil and Structural Engineering - CSE 2015

Copyright (C) Institute of Research Engineers and Doctors, USA .All rights reserved.

ISBN: 978-1-63248-057-6 doi: 10.15224/ 978-1-63248-057-6-49
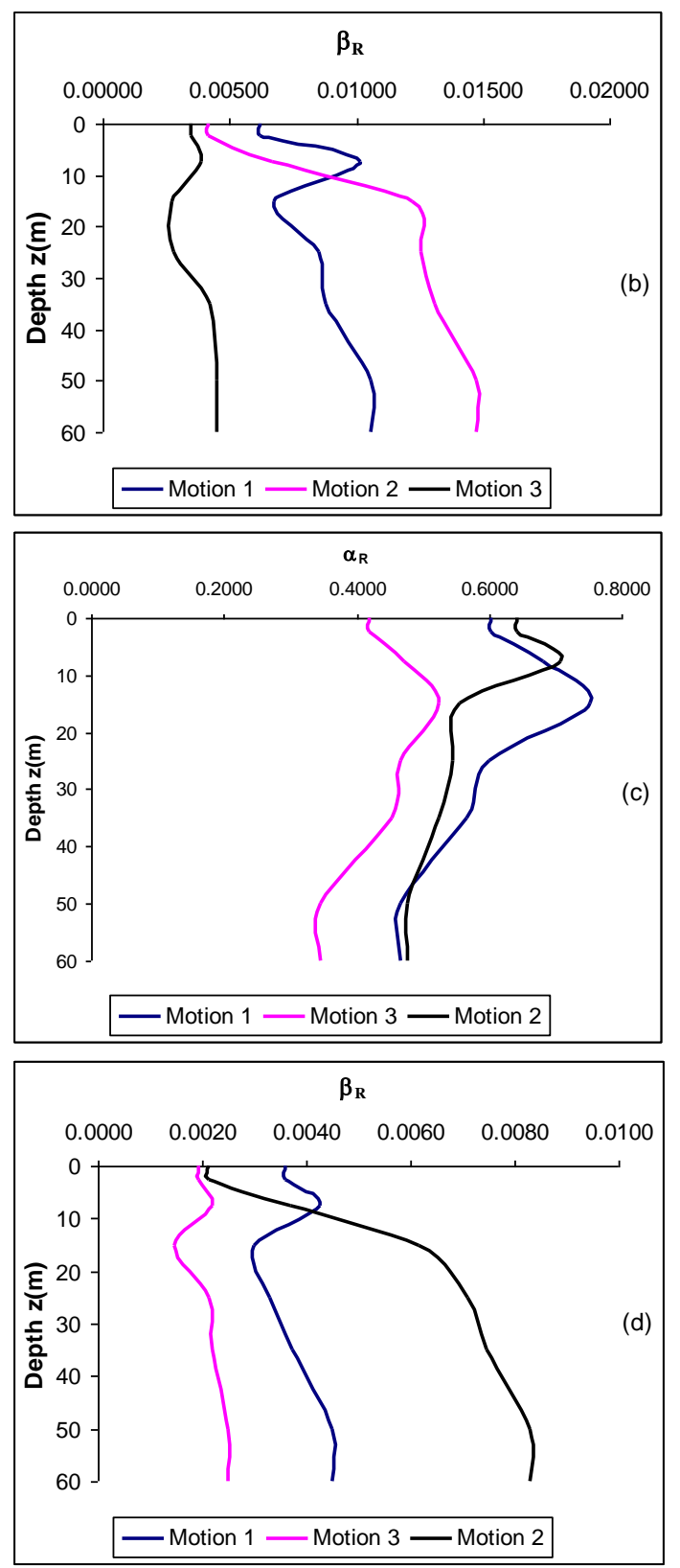

Fig. 8. $\alpha_{R}$ and $\beta_{R}$ profiles (a) $\alpha_{R}$ for soft clay; (b) $\beta_{\mathrm{R}}$ for soft clay; (c) $\alpha_{\mathrm{R}}$ for stiff clay; (d) $\beta_{\mathrm{R}}$ for stiff clay

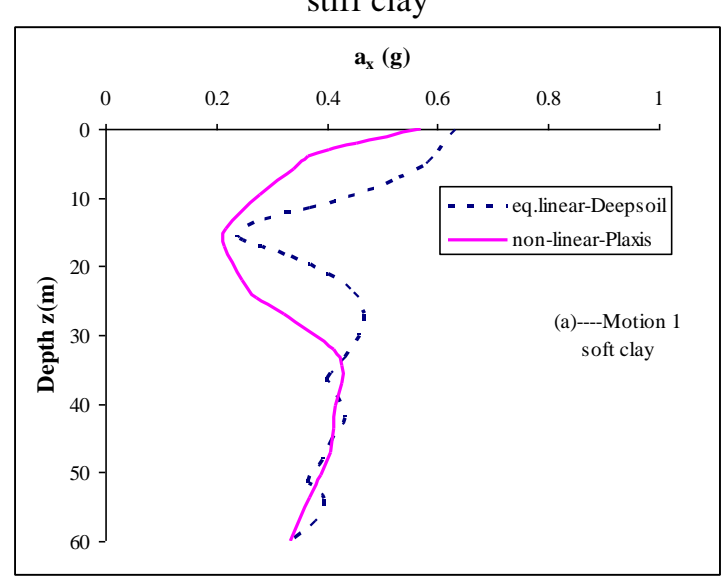

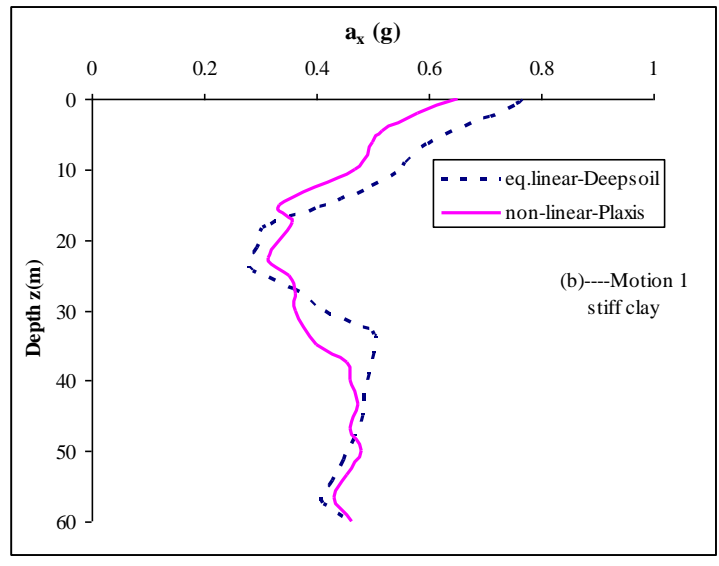
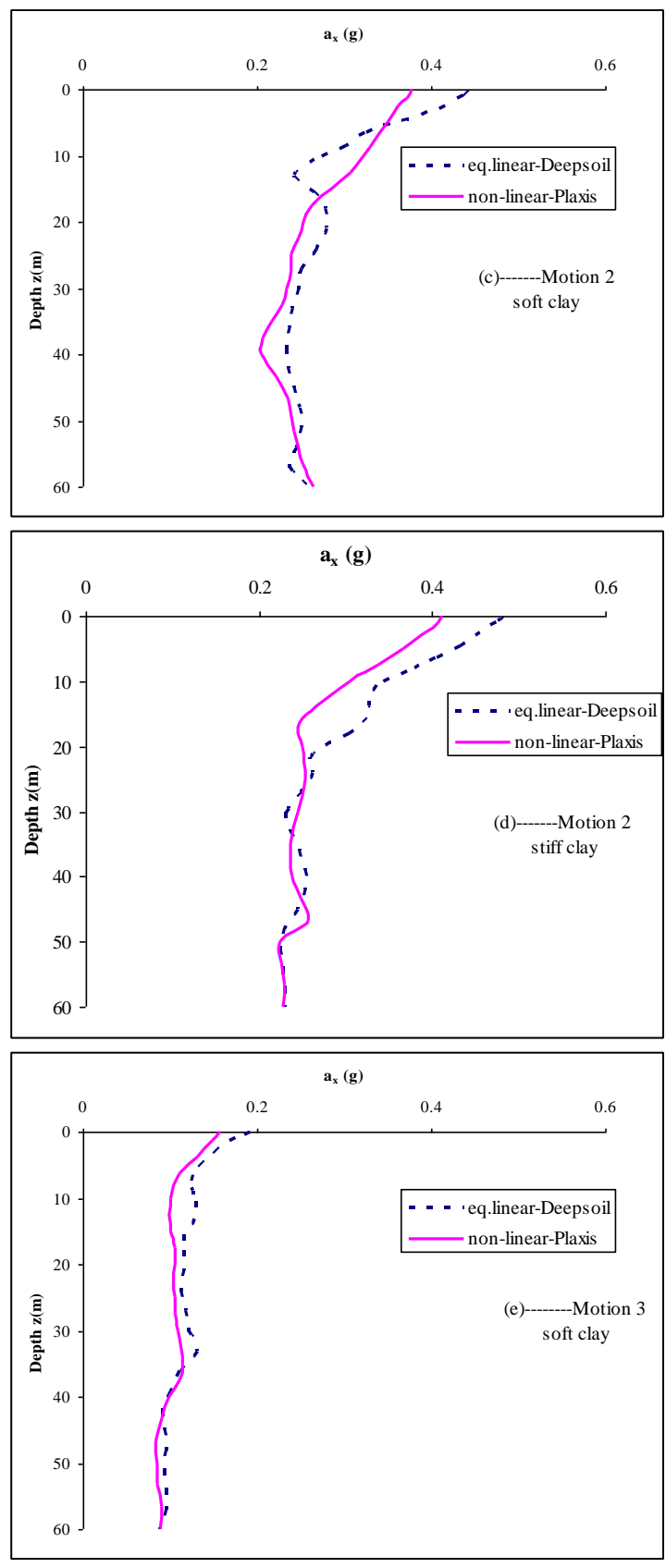
Proc. of the Third Intl. Conf. on Advances in Civil and Structural Engineering - CSE 2015

Copyright (C) Institute of Research Engineers and Doctors, USA .All rights reserved.

ISBN: 978-1-63248-057-6 doi: 10.15224/ 978-1-63248-057-6-49

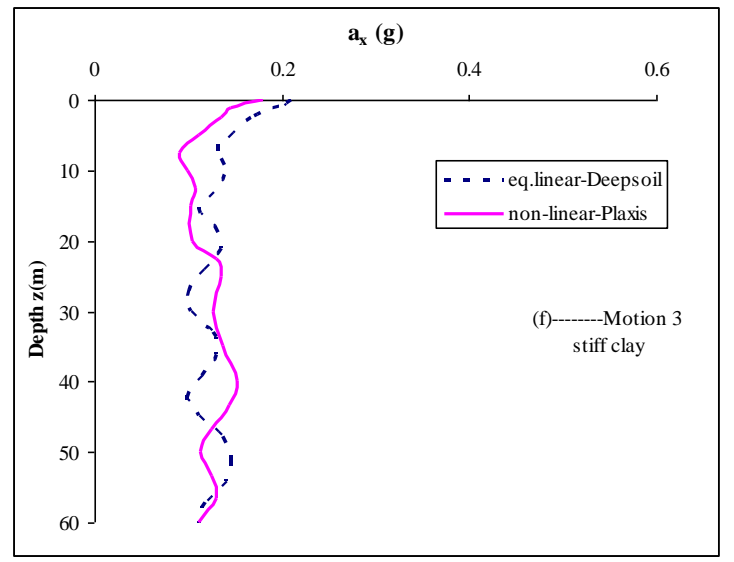

Fig. 9. Profiles of Peak ground acceleration for the studied cases.
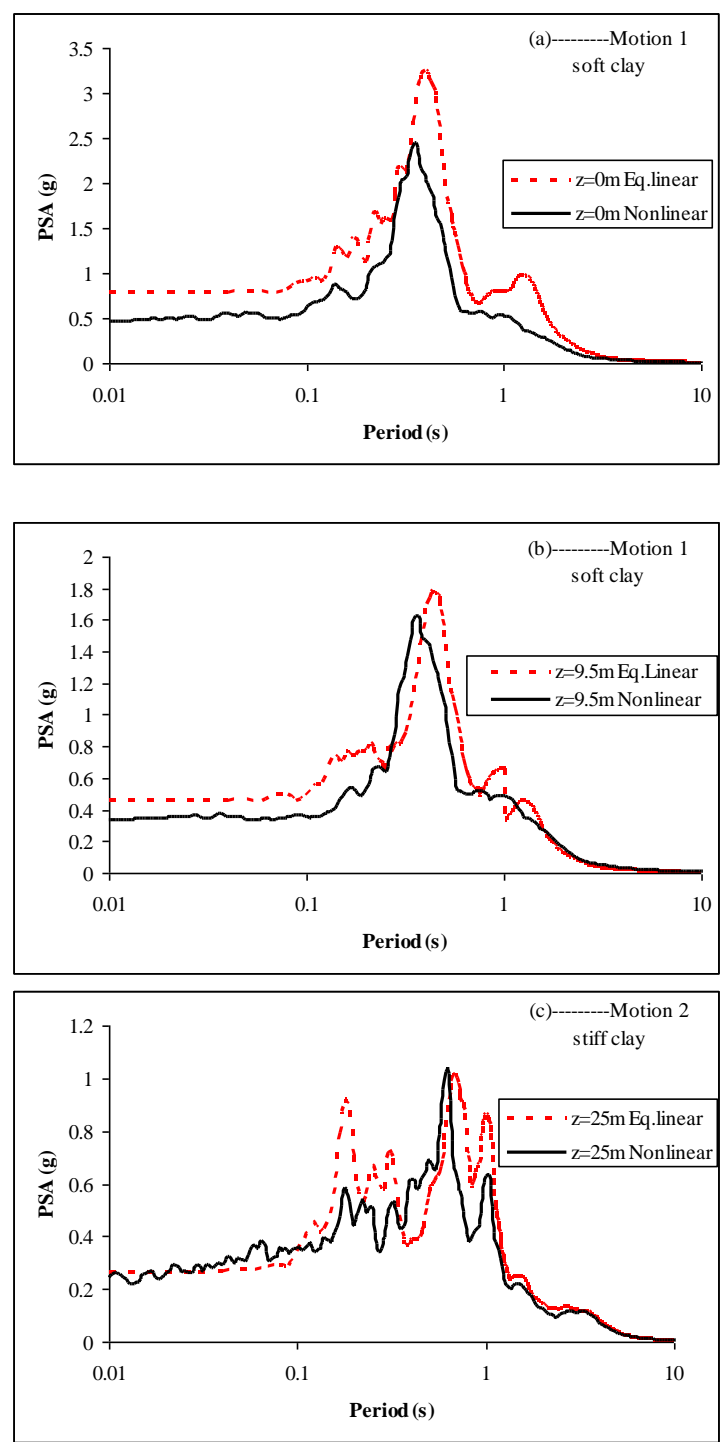
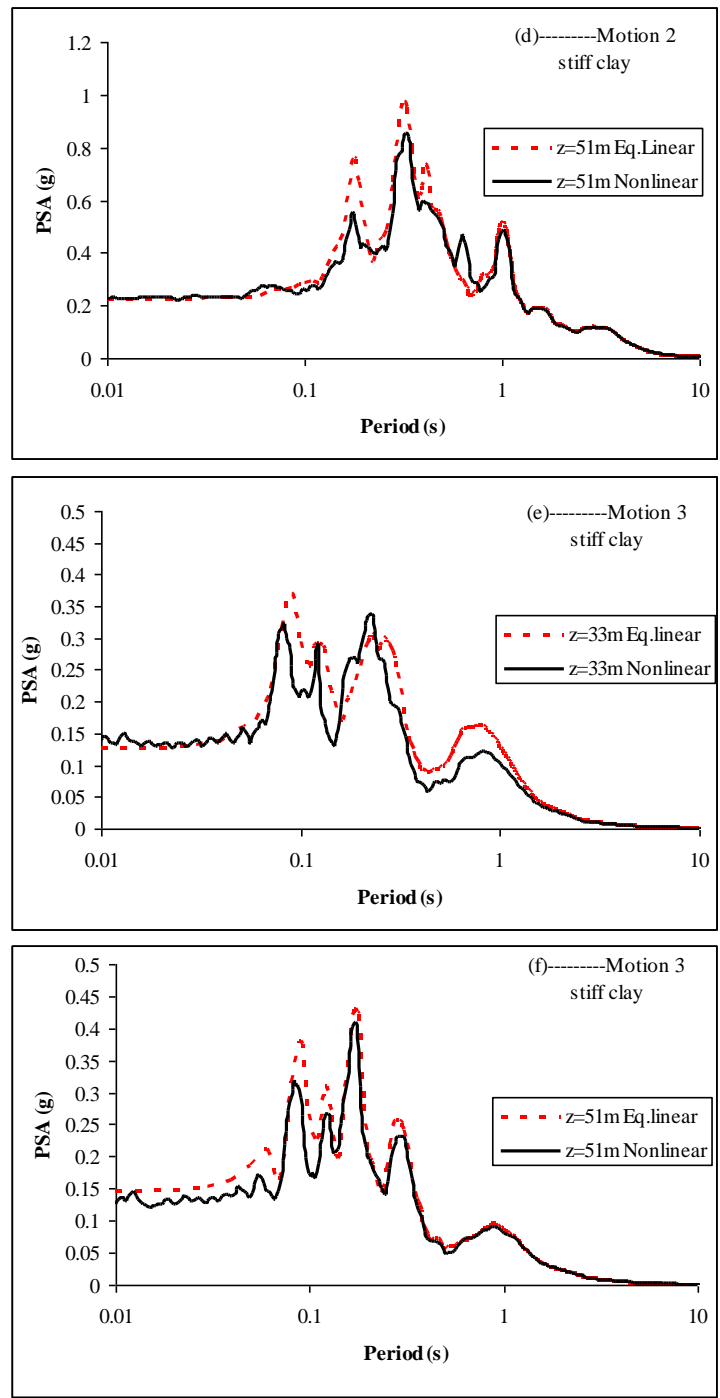

Fig. 10. Comparison between response spectra obtained with 1D equivalent linear analysis and 2D nonlinear analysis

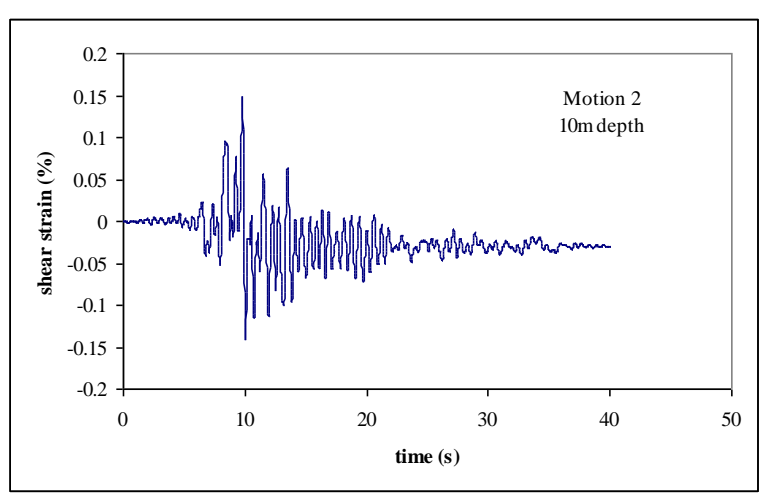

Fig. 11.Variation of shear strain with time for soft clay deposit and $10 \mathrm{~m}$ depth. 


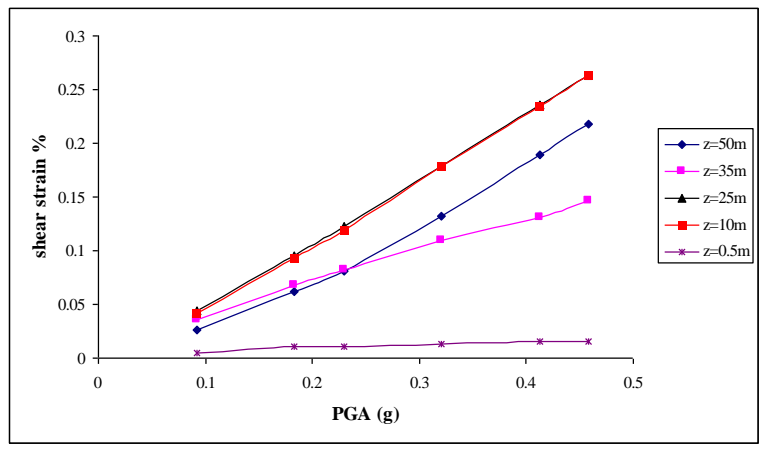

Fig. (12) Effect of peak ground acceleration on the maximum shear strain for stiff clay deposit.

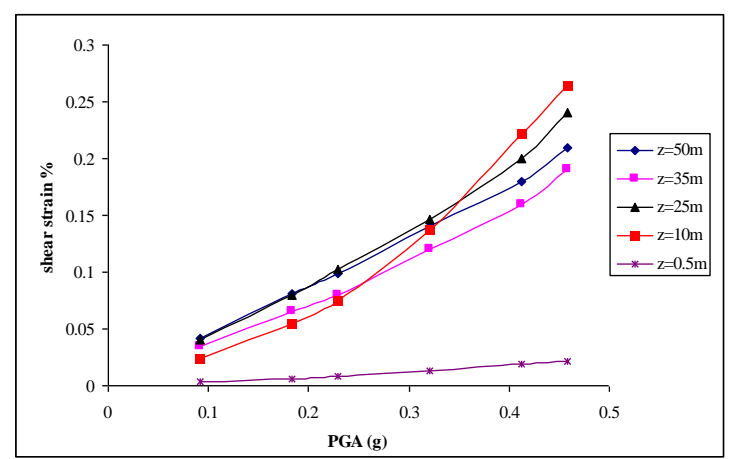

Fig. 13. Effect of peak ground acceleration on the maximum shear strain for soft clay deposit.

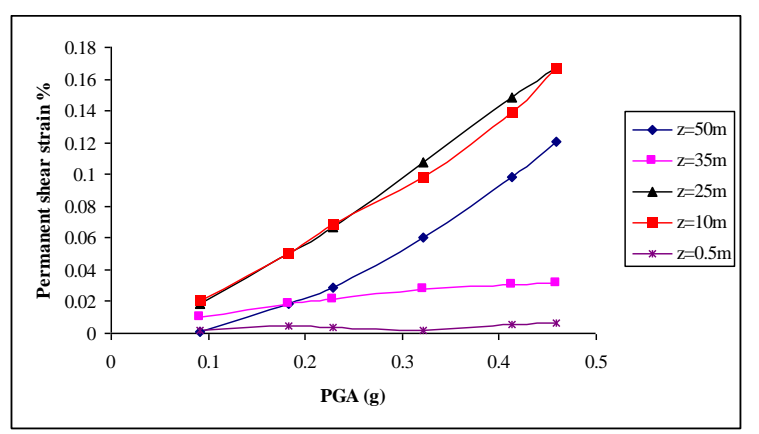

Fig. 14. Effect of peak ground acceleration on the permanent shear strain for stiff clay deposit.

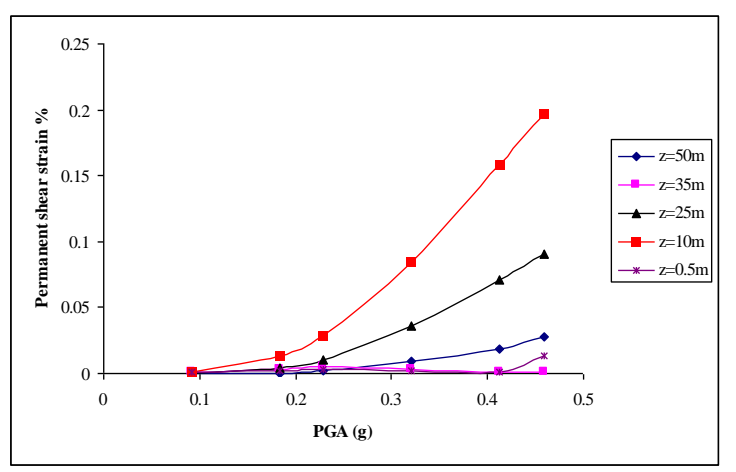

Fig. 15. Effect of peak ground acceleration on the permanent shear strain for soft clay deposit.

\section{Conclusions}

In this paper a set of nonlinear 2D dimensional finite element analyses were performed to describe the nonlinear behavior of soil deposits during and after ground shaking. The stiffness values and the amount of viscose damping are investigated in equivalent linear analysis using 1D analysis to calibrate the plastic analysis models using 2D analysis. The comparison between nonlinear and equivalent linear analysis for three different acceleration time histories was also presented. The effect of peak ground acceleration on the maximum and permanent shear strain was investigated. Almost results showed a contraction of peak ground acceleration profile and the spectra as compared to the equivalent linear analysis especially in the uppermost portion of the deposit. For lowermost portion a good agreement between the results obtained by equivalent linear solution and those obtained by the $2 \mathrm{D}$ nonlinear solution was observed.

The maximum and permanent shear strain induced in the soil increases as increase of peak ground acceleration. The rate of increase in shear strain increases as increase of peak ground acceleration for soft soil and linearly for stiff clay therefore, the results obtained by the equivalent linear analysis should not be considered as a right way to modeling strong motion earthquakes especially for soft clay deposit because the nonlinear analysis does not account for the change in soil properties during the of ground motion.

\section{References}

[1] Phanikanth V, Deepankar Choudhury G, Rami Reddy G. Equivalent-Linear Seismic Ground Response Analysis of Some Typical Sites in Mumbai. Geotechnical and Geological Engineering 2011; 29:1109-1126

[2] Choudhury D, Savoikar P. Equivalentlinear seismic analyses of MSW landfills using DEEPSOIL. Eng Geol 2009; 107(3-4):98-108

[3] Madabhushi SPG, Zeng X. Simulating seismic response of cantilever retaining walls. J Geotech Geoenviron Eng 2007;133(5):539-49.

[4] Elgamal AW, Parra E, Yang Z, Adalier $K$. Numerical analysis of embankment foundation liquefaction countermeasures. J Earthquake Eng 2002;6(4): 447-71.

[5] Amorosi A., Boldini D. Numerical modelling of the transverse dynamic 
Proc. of the Third Intl. Conf. on Advances in Civil and Structural Engineering - CSE 2015

Copyright (C) Institute of Research Engineers and Doctors, USA .All rights reserved.

ISBN: 978-1-63248-057-6 doi: 10.15224/ 978-1-63248-057-6-49

behaviour of circular tunnels in clayey

soils. Soil Dyn Earthq Eng

2009;29(6):1059-1072.

[6] A. F. Zidan "Numerical study of

Behavior of circular footing on geogridreinforced sand under static and dynamic loading" Geotechnical and Geological Engineering, 2012, 30 (2): 499-510

[7] Prevost, J.H., Abdel-Ghaffar, A.M. and Lacy, S.J., Nonlinear dynamic analysis of earth dams: a comparative study. Journal of Geotechnical Engineering, ASCE, 1985, 111(2), 882-897

[8] Daddanzio, R.P., Ettouney, M. M. and Sandler, I.S., Nonlinear dynamic slope stability analysis. Journal of Geotechnical Engineering, ASCE, 1987, 113(4), 285 298

[9] Elgamal, A.M., Scott, R.F., Succarieh, M.H. and Yan, L.P., La Villita dam response during five earthquake including permanent deformation. Journal of Geotechnical Engineering, ASCE 1990, 116(10), 1443 - 1462.

[10] Kokusho T (2004) Nonlinear site response and strain dependent soil properties. Current Science 2004;87(10):1363-1369

[11] Park D, Hashash YMA. Soil damping formulation in nonlinear time domain site response analysis. Journal of Earthquake Engineering 2004; 8:249-274.

[12] Ciro Visone, Filippo Santucci de Magistris, and Emilio Bilotta., comparative study of frequency and time domain analysis for seismic site response, EJGE, Vol. 15 2010. Bund. A

[13] Amorosi A., Boldini D., Elia G., Parametric study on seismic ground response by finite element modelling. Computer and Geotechnics 2010;37(6):515-528.

[14] Kramer, S.L. (1996) Geotechnical Earthquake Engineering, Prentice Hall, Inc., Upper Saddle River, New Jersey, 653 pp.

[15] Hashash YMA, Groholski DR, Philips CA, Park D (2008) DEEPSOIL v3.5beta, User manual and tutorial. University of Illinois, UC

[16] PLAXIS 2D. Reference manual, version $8 ; 2003$.

[17] Vucetic M, Dobry R. Effects of the soil plasticity on cyclic response. J Geotech Eng Div (ASCE) 1991;117(1):89-107.

[18] Idriss, I. M. and Seed, H. B. (1968) "Seismic response of horizontal soil layers." Journal of the Soil Mechanics and Foundations Division, ASCE, Vol. 94, No. SM4, pp 1003-1031.
[19] Seed, H.B., Idriss, I.M. (1970). Soil moduli and damping factors for dynamic response analysis, Report EERC 70-10. Earthquake Engineering Research Center.

[20] Schnabel, P. B., Lysmer, J. and Seed, H. B. (1972) "SHAKE: A computer program for earthquake response analysis of horizontally layered sites." Report No. EERC 72-12, Earthquake Engineering Research Center, University of California, Berkeley, California.

[21] Lysmer J, Kuhlemeyer RL. Finite dynamic model for infinite media. ASCE EM 1969;90:859-77.

[22] Lysmer J, Kuhlemeyer RL. Finite dynamic model for infinite media. ASCE EM 1969;90:859-77.

[23] Ross M. Modeling Methods for Silent Boundaries in Infinite Media. 2004 ASEN 5519-006: Fluid-Structure Interaction, University of Colorado at Boulder.

[24] Rayleigh L. Theory of sound, vol. 2. New York: Dover; 1945

[25] Hudson M, Idriss IM, Beikae M. User's manual for QUAD4M. Center for Geotechnical Modeling, University of California, Davis; 1994.

[26] Hashash YMA, Park D. Viscous damping formulation and high frequency motion propagation in nonlinear site response analysis. Soil Dyn Earthq Eng 2002;22(7):611-24. 